\title{
A UTILIZAÇÃO DA TECNOLOGIA VIRTUAL NO AUXÍLIO À FORMAÇÃO ACADÊMICA SUPERIOR NA ÁREA DE SAÚDE: RELATO DE UMA EXPERIÊNCIA
}

\author{
Hugo Silva Bicalho
}

Elioenai Dornelles Alves

\section{RESUMO:}

A internet tem servido com forte instrumento no auxílio ao desenvolvimento do conhecimento científico e tecnológico, servindo como facilitador na disseminação da informação. O presente estudo tem por objetivo identificar aspectos facilitadores e dificultadores na utilização da tecnologia virtual de forma a promover uma reflexão sobre os ganhos no processo de ensinoaprendizagem com a utilização dessa tecnologia. O estudo foi realizado a partir de um relato de experiência ocorrido na disciplina "Saúde da Comunidade 2" do curso de enfermagem da Universidade de Brasília. Concluindo-se que, mesmo mediante alguns empecilhos, a tecnologia virtual atua como grande facilitador no desenvolvimento do conhecimento científico fornecendo um suporte extra-institucional no processo de aprendizagem.

DESCRITORES: tecnologia virtual; tecnologia educacional; educação em enfermagem; enfermagem

THE USE OF VIRTUAL TECHNOLOGY IN THE AID OF SUPERIOR ACADEMIC FORMATION IN HEALTH SECTOR: EXPERIENCE REPORT

\begin{abstract}
The internet has served as a strong tool to aid the development of scientific and technological knowledge, serving as a facilitator in the dissemination of information. This study aims to identify advantages and constraints in the use of virtual technology in order to promote a reflection on the gains in the teaching-learning process using this technology. This study was conducted from an experience occurred in the course "Community Health 2" at Nursing school at Brasília University (UnB). We can conclude that, even through some setbacks, the
\end{abstract}


virtual technology acts as a great facilitator in the development of scientific knowledge by providing an extra-institutional support in the learning process.

KEY WORDS: virtual technology; educational technology; nursing education; nursing

\section{INTRODUÇÃO}

Presente no cenário brasileiro desde 1906, a Educação à distância - EAD, teve em seus primórdios a realização de cursos por correspondência, rádio e televisão, com enfoque voltado alfabetização e profissionalização de pessoas (VIANNEY, TORRES E SILVA, 2003). No Brasil, apenas nas duas últimas décadas houve uma grande disseminação dessa modalidade, em especial no ensino superior de graduação e pós-graduação (BARROS, 2007) no que diz respeito à utilização da tecnologia virtual como auxílio à estratégia de ensino.

Com a publicação da portaria 2.253 do Ministério da Educação (BRASIL, 2001), os cursos superiores já reconhecidos pelo MEC passaram a poder oferecer disciplinas que, no todo ou em parte, utilizavam-se de métodos não presenciais, desde que essas disciplinas não excedessem o total de $20 \%$ do tempo previsto para a integralização do currículo do curso (TORI, 2003). Com essa publicação a utilização da tecnologia virtual passou a ganhar espaço crescente nas instituições de ensino superior.

Atualmente, a internet tem servido com forte instrumento no auxílio do desenvolvimento do conhecimento científico e tecnológico, servindo como facilitador na disseminação da informação, proporcionando fortes alterações na sociedade através da reorganização do trabalho e do ensino.

Essas alterações sociais geram melhorias na produção e produtividade ao passo que desenvolve nos indivíduos atuantes no processo, o surgimento de novas competências e habilidades como a capacidade do trabalho em equipe, o desenvolvimento do senso critico e da criatividade, além de trabalhar os aspectos da comunicação social e auxiliar nas tomadas de decisão (UNESCO, 2002).

Enquanto que no ensino convencional, os acadêmicos são sempre abordados em grupo, no que se refere a ritmo, tempo e material educacional. A educação virtual permite um contato mais individualizado entre o tutor e o acadêmico, forçando com que haja a necessidade de capacitação de ambos para que aprendam a trabalhar com as diferenças, sob o 
ponto de vista de experiência profissional, de vida, cultural e de habilidades (BASTOS E GUIMARÃES, 2003).

O presente trabalho tem por finalidade reafirmar a importância da educação a distância - EAD, como um rico auxílio no campo da relação dialógica junto aos acadêmicos e como estratégia pedagógica eficaz da utilização da tecnológica virtual na promoção do fomento ao conhecimento. Para isto busca refletir acerca da utilização da internet como instrumento auxiliar no fomento à educação de ensino superior.

\section{OBJETIVO GERAL:}

Promover a reflexão sobre os ganhos no processo de ensino-aprendizagem com a utilização da tecnologia virtual.

\section{OBJETIVOS ESPECÍFICOS:}

Identificar aspectos facilitadores na utilização da tecnologia virtual; Identificar aspectos dificultadores na utilização da tecnologia virtual;

\section{METODOLOGIA}

Considerando todos os aspectos destacados e o objetivo proposto, utilizou-se a metodologia de pesquisa qualitativa que tem por desígnio proporcionar maior proximidade com o problema, com vista a torná-lo mais claro. "O planejamento para este tipo de trabalho é bastante flexível, de modo que possibilite a consideração dos mais variados aspectos relativos ao fato estudado" (GIL, 2002, p. 41).

$\mathrm{O}$ presente trabalho consiste em um relato de experiência de uma prática acadêmica ocorrida na disciplina Saúde da Comunidade 02, do oitavo semestre, do curso de enfermagem ministrado na Universidade de Brasília. A disciplina ocorreu no $2^{\circ}$ semestre de 2009.

\section{RESULTADOS E DISCUSSÃO}

Relato da Experiência

\section{A disciplina:}


A disciplina Saúde da Comunidade 2 é ministrada na Universidade de Brasília para acadêmicos do último semestre de graduação do curso de enfermagem, oitavo semestre, de acordo com a grade curricular, ainda vigente, mas em transição, instituída no primeiro semestre de 1962.

Ministrada no primeiro semestre de 2009, a disciplina visa analisar os aspectos relevantes a saúde da comunidade em um contexto político-econômico de saúde no período desde 1891 até os dias atuais incorporando os conhecimentos relacionados à teoria e a prática de enfermagem em saúde da comunidade e conhecer os diferentes campos de atuação da enfermagem em saúde a comunidade nos serviços de saúde.

A disciplina era divida em três momentos temporais distintos, mas interrelacionados e co-dependentes entre si: aula teórica expositiva, no intuito de fornecer a base inicial do processo de ensino; aula prática em campo de estágio, momento no qual o acadêmico se dirige a comunidade, dentro da modalidade de atenção básica, realizando em visitas domiciliares no intuito de visualizar, analisar, discutir e implementar na prática, consultas e diagnósticos de enfermagem focados em estratégias de promoção da saúde, amplamente debatidas em sala de aula e no ambiente virtual; preenchimento de portfólio eletrônico, por meio do qual os acadêmicos possuíam espaço para interação com os tutores e acadêmicos, postagem de atividades desenvolvidas, debate de assuntos de interesse científico e acesso a textos, aulas e manuais visando o suporte bibliográfico de forma rápida e acessível.

As atividades teórico-práticas-virtuais eram intercaladas ao longo do semestre, sendo a utilização do portfólio eletrônico uma estratégia dinâmica, cuja finalidade visava eliminar barreiras geográficas instituindo o aprendizado coletivo ou individual, sinalizando uma inovação dos modelos tradicionais de ensino, treinamento e capacitação (Andrade, 2000).

Os tutores:

A disciplina foi composta por um professor titular e por duas professoras substitutas. Esses professores estavam presentes em todas as atividades, teóricas, práticas e virtuais, exercendo o papel de tutores no que diz respeito às atividades virtuais.

No momento teórico em sala de aula, os professores se revezavam para ministrar os conteúdos propostos pela ementa. 
Nas atividades práticas de campo de estágio, os três professores estavam presentes e se distribuíam, junto aos acadêmicos em grupos menores para iniciarem as visitas domiciliares.

$\mathrm{Na}$ área virtual, todos os professores, assumindo o papel de tutores, serviam de agentes facilitadores ao conhecimento, orientando os acadêmicos frente à suas dúvidas e servindo de norteadores do processo ensino-aprendizagem. Todos os tutores possuíam ampla qualificação e experiência na modalidade de EAD.

A relação foi de três professores/tutores para 19 acadêmicos, sendo a tutoria virtual compartilhada entre os professores, transformando-os em co-responsáveis pela facilitação do processo ensino-aprendizagem, primando pelo acompanhamento do grupo de acadêmicos em sua totalidade.

As estratégias motivadoras desempenhadas pelos tutores são fundamentais para se garantir a continuidade do ensino virtual de qualidade propiciando a análise, a problematização e a reflexão do conhecimento (OLIVEIRA, DIAS E FERREIRA, 2004), transformando a utilização do espaço virtual em espaço potencializador da capacidade de aprendizado e de fomento do conhecimento.

Aspectos facilitadores da utilização da tecnologia virtual:

Flexibilidade no horário de postagem das atividades:

Esse momento da disciplina é altamente flexível e perfeitamente adaptável a realidade individual de cada acadêmico, fazendo com que em qualquer momento das 24 horas do dia o acadêmico possa recorrer ao portfólio eletrônico para postar suas atividades.

Estimulo a realização de práticas pedagógicas renovadas:

Dinamicidade do processo interativo no contato com os tutores, facilitando a busca pelo estabelecimento de uma relação dialógica efetiva e eficaz no processo de configuração e desenvolvimento do conhecimento.

$>$ Autonomia de manipulação da tecnologia virtual:

Por meio da busca, armazenamento, modificação e seleção de informações de conteúdo científico de relevância.

Utilização de uma tecnologia de forte tendência contemporânea:

A tecnologia virtual encontra-se presente e difundida no cotidiano das pessoas, seja em seus celulares, computadores portáteis ou tradicionais, a tecnologia virtual se faz presente na maioria dos locais. 
Aspectos dificultadores da utilização da tecnologia virtual:

Dificuldades de cadastramento na modalidade virtual da disciplina:

Para ter acesso ao espaço virtual se fazia necessário o cadastramento do acadêmico na plataforma eletrônica onde a disciplina estava alocada. Muitas vezes o processo de cadastramento não era concluído ou invalidado por imperícia e incapacitação dos acadêmicos ou do suporte tecnológico oferecido pela instituição.

Decessidade do desenvolvimento da maturidade:

$\mathrm{Na}$ busca por um estudo individualizado, independente e autônomo, o acadêmico possui algumas atividades obrigatórias para postar no portfólio eletrônico, entretanto o espaço também deve ser utilizado como espaço de debates e discussão visando desenvolver o conhecimento. Por não se tratar de uma obrigatoriedade esse espaço de debate, muitas vezes, é colocado de forma marginalizada diante das demais atividades.

A partir do momento em que o acadêmico restringe suas atividades a postar apenas o que é solicitado e mantendo contato apenas com o tutor, fazendo com que haja pouca interatividade entre acadêmicos, sendo maior a relação tutor/acadêmico.

Desmotivação no processo de ensino virtual:

\section{CONCLUSÃO}

Com o alto desenvolvimento tecnológico encontrado em todos os setores da sociedade, a saúde e a educação não teriam como ficar de fora. Cada vez mais a tecnologia virtual interage como forte aliada no processo do desenvolvimento científico, aproximando o conhecimento daqueles que buscam o aprendizado.

A comodidade da utilização do portfólio eletrônico e das atividades não teve por pretensão substituir a educação presencial teórico-prática, mas sim fornecer um suporte extrainstitucional visto que ambas são modalidades de um mesmo processo (CASTANHEIRA E SELEME, 2007).

A utilização da tecnologia virtual tem possibilitado a reabilitação de altos níveis de interatividade e integração entre os sujeitos envolvidos dentro do processo pedagógico, favorecendo a criação de novos ambientes cognitivos que visam o estabelecimento de novas formas de pensar e aprender. Portanto, mesmo diante de alguns aspectos dificultadores, o 
ganho intelectual pedagógico, compensa em muito a utilização da tecnologia virtual no auxílio do processo de aprendizado.

\section{REFERÊNCIAS}

BARROS, V.A. O trabalho do docente virtual: análise jurídica das condições de trabalho decorrentes do sistema de educação a distância. In: XVI CONGRESSO NACIONAL DO CONSELHO NACIONAL DE PESQUISA E PÓS-GRADUAÇÃO EM DIREITO, 2007, Belo Horizonte, Anais... - Florianópolis: Fundação Boiteux, 2008. 1 CD-ROM .

BASTOS, M.A.R.; GUIMARÃES, E.M.P. Educação a distância na área da enfermagem: relato de uma experiência. Revista Latino Americana de Enfermagem, São Paulo, v.11, n.5 p.685-691, 2003.

BORGES-ANDRADE, J. E. Desenvolvimento de medidas em avaliação de treinamento. Revista Estudos de Psicologia, Natal, v. 7, n. especial, p.31-43, 2000.

BRASIL. Portaria ${ }^{\circ}$ 2.253, de 18 de outubro de 2001. Diário Oficial da União, Poder Executivo - Ministério de Estado da Educação, Brasília, DF, 19 outubro 2001. Seção1, p. 1819.

CASTRO NEVES, C. M. de. Critérios de Qualidade para a Educação à Distância. In Tecnologia Educacional - ABT: Rio de Janeiro - v. 26, no. 141, abr/jun, 1998.

CASTANHEIRA, N. P.; SELEME, R. Educação à distância: a utilização adequada dos tempos para a capacitação e a disseminação do conhecimento. In. $13^{\circ}$ CONGRESSO INTERNACIONAL DE EDUCAÇÃO Å DISTÂNCIA; 2007 abril, 2007. Disponível em <http://www.abed.org.br/congresso2007/tc/52200732907PM.pdf>. Acesso em: 12 março 2010.

FREIRE, P. Pedagogia da autonomia: saberes necessários à prática educativa. São Paulo: Paz e Terra, 2007.

GIL, A. C. Como classificar as pesquisas? In: Como elaborar projetos depesquisa.4.ed. São Paulo: Atlas, 2002. p. 41-57.

United Nations Educational Scientific and Cultural Organization (UNESCO). Information and communication technology in education: a curriculum for schools and programme of teacher development. Paris; 2002.

VIANNEY, J.; TORRES P.; SILVA, E. A universidade virtual no Brasil: os números do ensino superior a distância no país em 2002. In: SEMINÁRIO INTERNACIONAL SOBRE UNIVERSIDADES VIRTUAIS NA AMÉRICA LATINA E CARIBE; 2003 fevereiro 13-14; Quito, Equador. Anais... Quito, 2003. p. 74-87.

OLIVEIRA, E.S.G. de; DIAS, A.C.S; FERREIRA, A.C.R. A importância da ação tutorial na educação a distância: discussão das competências necessárias ao tutor. In: VII CONGRESSO IBEROAMERICANO DE INFORMÁTICA EDUCATIVA, 2004, México. 
Disponível em: <http://www.niee.ufrgs.br/ribie2004/trabalhos/comunicações/com20-28.pdf>. Acesso em: 28 março 2010.

TORI, R, O virtual que marca presença. Revista de Educação à distância - ABED, São Paulo, v.2, n.1, maio 2003. 